Research Article

\title{
An Interval Efficiency Measurement without Sign Restrictions in Data
}

\author{
Liyang Yang $\mathbb{D i D}^{1}$ and Renbian Mo $\mathbb{i D}^{2}$ \\ ${ }^{1}$ School of Statistics, Southwestern University of Finance and Economics, Chengdu 611130, China \\ ${ }^{2}$ School of Business Administration, Southwestern University of Finance and Economics, Chengdu 611130, China \\ Correspondence should be addressed to Renbian Mo; morenbian@foxmail.com
}

Received 7 September 2019; Revised 20 December 2019; Accepted 23 December 2019; Published 22 January 2020

Academic Editor: Krzysztof Puszynski

Copyright (c) 2020 Liyang Yang and Renbian Mo. This is an open access article distributed under the Creative Commons Attribution License, which permits unrestricted use, distribution, and reproduction in any medium, provided the original work is properly cited.

\begin{abstract}
Mostly, all conventional DEA models assume that input-output data are precise and nonnegative, but in real-life application, this condition is mostly not applicable. Through progressive development in the methodology of DEA, some models separately deal with imprecise and negative data. In this study, the IMSBM model is proposed to evaluate the performance of a set of homogenous DMUs with imprecise and negative input-output data. The IMSBM model is far superior to models with similar capability because it considers the inefficiency caused by both radial and nonradial slacks. The lower and upper bounds of interval efficiency calculated by the IMSBM model reflect the performance of observed DMU in most unfavourable and most favourable situations. Further, it is proved that the IMSBM model is units invariant, monotone, and translation invariant. Moreover, we elaborate both bounds of the interval efficiency are in the range of $[0,1]$. The degree of preference approach is introduced to rank the DMUs. In addition, we compare the interval efficiency scores calculated by the IMSBM model and the interval SORM model and explain the reason for the difference between the scores. By adjusting the weights of inputs and outputs, it is found that only inefficiency scores fluctuate with slack weights.
\end{abstract}

\section{Introduction}

Due to limited production resources, efficiency is a key factor for both public and private sector organisations. There are numerous techniques to measure the efficiency of a particular decision making unit (DMU), and one of the popular mathematical tools is known as data envelopment analysis (DEA). DEA is widely used to compare the performances of a set of homogenous DMUs by calculating the relative efficiency. With multiple-inputs and multiple-outputs, DEA can measure the relative efficiency of DMUs by using a ratio of the weighted sum of outputs to the weighted sum of inputs, and an efficient DMU always uses less inputs to produce a specific amount of outputs or produce more outputs using equal amount of inputs, as compared to other observed DMUs. However, two priori assumptions limit the application of conventional DEA models: (1) precise inputoutput data and (2) nonnegative input-output data.
The conventional DEA models assume that input-output data should be precise. However, in real-life situations, it is not always possible. So, we often see bounded (interval), ordinal, and ratio bounded data in applications $[1,2]$. Therefore, the assumption of precise data limits the application of conventional DEA models. To deal with this concern, Cooper et al. [3] firstly introduced imprecise DEA (IDEA) to cope with imprecise data, and there were several papers presented on the theoretical development of this method. Despotis and Smirlis [4] transformed classical CCR (Charnes et al. [5]) model into the case of interval data straightforwardly, and the proposed model gave the natural outcome of lower and upper bounds of efficiency scores. However, the transformation was applied only to variables. Wang et al. [6] developed a pair of interval models, and it was addressed in this work that ordinal preference information and fuzzy data could be converted into interval data through scale transformation and $\alpha$-level sets, 
respectively. Jahanshahloo et al. [7] suggested the interval generalised DEA (IGDEA) model which treated the basic DEA models, specifically CCR model, BCC model (Banker et al. [8]), and free disposal hull (FDH) model [9], with interval data in a unified way. Aghayi et al. [10] presented a robust DEA model with a common set of weights (CSWs) under varying degrees of conservatism, and the interval data were used to represent data uncertainty. Azizi and Amirteimoori [11] and Toloo et al. [12] proposed DEA models to measure the relative efficiency of DMUs with flexible measures (also called dual-role factors) using interval inputoutput data. Shabani et al. [13] also proposed a common set of weights imprecise DEA (CSW-IDEA) to handle imprecise data. The models mentioned above were not slacks-based, indicating they could only measure the radial efficiency, but nonradial slacks were not accounted for. Tone [14] proposed a slacks-based measure (SBM) of efficiency. One of the advantages of the SBM model was that it put aside the assumption of proportionate changes in inputs and outputs and dealt with slacks directly. Lotfi et al. [15] developed an interval DEA model based upon the SBM model, and the DMUs were classified into three subsets according to the lower and upper bounds of the interval efficiency. Azizi et al. [16] generalised the SBM model into imprecise data to measure the performance of the DMUs, and the same constraint sets were used for maintaining the comparability.

Apart from the assumption of precise data, conventional DEA models assume that all inputs and outputs of DMUs are nonnegative. However, in real-life problems, this is not possible all the time, for example, when net profit acts as an output variable while loss happens. Traditionally, negative values are transformed into positive through data transformation [17], but somehow, such transformation impacts the solution of the objective function. Pastor and Ruiz [18] pointed out that the translation invariance property allowed a DEA model to deal with negative data. Cheng et al. [19] developed a variant of radial measure (VRM) to deal with variables that could be negative or nonnegative for different DMUs. Although the VRM input-oriented model was output translation invariant and the output-oriented model was input translation invariant, there were still some limitations while measuring the relative efficiency. The efficiencies given by the input-oriented VRM model might be negative [20] and the efficiencies given by the output-oriented VRM model could be in the range of $[0.5,1][21]$. To avoid these drawbacks, Tung et al. [21] further defined two efficiency measures for input-oriented and output-oriented VRM models. Although the models mentioned above can deal with negative data and some of them are translation invariant, they are not slacks-based models and ignore the inefficiency caused by nonradial slacks. Sharp et al. [22] introduced the idea of the range of possible improvement [23] into the SBM model. They developed a modified slacks-based measure (MSBM) model to evaluate DMUs with negative data. The MSBM model took into account input and output slacks and possessed the property of translation invariant.

Most existing works addressed only imprecise data or only negative data, and hardly any models considered these two characters simultaneously. Hatami-Marbini et al. [24] developed the interval semioriented radial measure (interval SORM) model to evaluate efficiency in the presence of interval data without sign restrictions. Although the interval SORM model was able to evaluate the efficiency with negative data, it only revealed the radial efficiency and failed in considering the inefficiency caused by nonradial slacks.

This study extended the MSBM model into an imprecise framework to evaluate the efficiency of particular DMUs with interval data. Compared with existing interval DEA models, the interval modified slacks-based measure (IMSBM) model considers both radial and nonradial efficiency from the perspective of slacks and is translation invariant to cope with the existence of negative data. There are existing studies that illustrate that ordinal preference and fuzzy data can be converted into interval data $[6,25,26]$. Therefore, the IMSBM model focuses on interval data in this paper.

The rest of this paper is organised as follows. In Section 2, the IMSBM model is presented and proved to possess basic properties as an efficiency measurement. Section 3 classifies DMUs into three subsets, and the degree of preference approach is introduced to rank interval efficiencies. A numerical illustration is exemplified in Section 4. Moreover, in the last section, the findings of our study are concluded.

\section{IMSBM Model}

As Färe et al. [27] pointed out that there was an assumption of the constant returns to scale (CRS) that any DMU could be radially expanded or contracted to form other feasible ones, which caused inconsistency when negative data exist. However, it is not the case under variable returns to scale (VRS). Therefore, the models mentioned below are assigned under the VRS.

2.1. MSBM Model with Precise Data. Firstly, we illustrate the MSBM model constructed by Sharp et al. [22].

Consider a set of $n$ homogenous units under analysis, and each of them consumes varying amounts of $m$ different inputs to produce varying amounts of $s$ different outputs. Specifically, $\operatorname{DMU}_{j}(j=1,2, \ldots, n)$ consumes $x_{i j}(i=1$, $2, \ldots, m)$ of each input to produce $y_{r j}(r=1,2, \ldots, s)$ of each output.

Generalising the SBM model to the case of nonpositive input-output data is not straightforward. Firstly, the translation invariant is not consistent when zero exists. Secondly, the optimal value can become negative with the existence of negative data [22]. Introducing the ideal point into the SBM model is fruitful in overcoming the drawbacks. For a given dataset, the ideal point is considered as $I=$ $\left(\min _{j} x_{i j}(i=1,2, \ldots, m), \max _{j} y_{r j}(r=1,2, \ldots, s)\right)$. Therefore, for $\mathrm{DMU}_{k}$, the range of possible improvement is defined as

$$
\begin{array}{ll}
R_{i k}^{-}=x_{i k}-\min _{j}\left\{x_{i j}\right\}, & i=1,2, \ldots, m, \\
R_{r k}^{+}=\max _{j}\left\{y_{r j}\right\}-y_{r k}, & r=1,2, \ldots, s .
\end{array}
$$


Obviously, $R_{i k}^{-} \geq 0$ and $R_{r k}^{+} \geq 0$ measure the distance from $\mathrm{DMU}_{k}$ to the ideal point. Replacing corresponding terms in the SBM model by $R_{i k}^{-}$and $R_{r k}^{+}$, the MSBM model is

$$
\begin{array}{ll}
\min & \rho_{k}=\frac{1-\sum_{i=1}^{m}\left(w_{i} s_{i k}^{-}\right) / R_{i k}^{-}}{1+\sum_{r=1}^{s}\left(v_{r} s_{r k}^{+}\right) / R_{r k}^{+}} \\
\text {subject to } \begin{cases}x_{i k}=\sum_{j=1}^{n} x_{i j} \lambda_{j}+s_{i k}^{-}, & i=1,2, \ldots, m, \\
y_{r k}=\sum_{j=1}^{n} y_{r j} \lambda_{j}-s_{r k}^{+}, & r=1,2, \ldots, s, \\
\sum_{j=1}^{n} \lambda_{j}=1, & \\
s_{i k}^{-}, s_{r k}^{+}, \lambda_{j} \geq 0, & \end{cases}
\end{array}
$$

where $s_{i k}^{-}$and $s_{r k}^{+}$are slacks in the $i^{\text {th }}$ input and $r^{\text {th }}$ output of $\mathrm{DMU}_{k}$, respectively. The weights of each input $w_{i}$ and of each output $v_{r}$ are determined subjectively by decision makers and subject to $\sum_{i=1}^{m} w_{i}=1, \sum_{r=1}^{s} v_{r}=1, w_{i} \geq 0$, and $v_{r} \geq 0$.

Note that when $R_{i k}^{-}=0$ or $R_{r k}^{+}=0$, it is assumed that the corresponding $\left(w_{i} s_{i k}^{-}\right) / R_{i k}^{-}$or $\left(v_{r} s_{r k}^{+}\right) / R_{r k}^{+}$is dropped from the numerator or denominator.

2.2. MSBM Model with Interval Data. Due to the lack of sufficient information in some complex systems, imprecise mathematics seems more appropriate to reality. The inputs and outputs are assumed to be interval variables denoted as $x_{i j} \in\left[\underline{x}_{i j}, \bar{x}_{i j}\right]$ and $y_{r j} \in\left[\underline{y}_{r j}, \bar{y}_{r j}\right]$, where $\underline{x}_{i j}$ is the lower bound of $x_{i j}, \bar{x}_{i j}$ is the upper bound of $x_{i j}, \underline{y}_{r j}$ is the lower bound of $y_{r j}$, and $\bar{y}_{r j}$ is the upper bound of $y_{r j}$. In this case, the ideal point in IMSBM model is considered as $I=\left(\min _{j} \underline{x}_{i j}(i=1,2, \ldots, m), \max _{j} \bar{y}_{r j}(r=1,2, \ldots, s)\right)$.

Consequently, for $\mathrm{DMU}_{k}$, the range of possible improvement is defined as

$$
\begin{aligned}
& {\left[\underline{R}_{i k}^{-}, \bar{R}_{i k}^{-}\right]=\left[\underline{x}_{i k}-\min _{j}\left\{\underline{x}_{i j}\right\}, \bar{x}_{i k}-\min _{j}\left\{\underline{x}_{i j}\right\}\right], \quad i=1,2, \ldots, m,} \\
& {\left[\underline{R}_{r k}^{+}, \bar{R}_{r k}^{+}\right]=\left[\max _{j}\left\{\bar{y}_{r j}\right\}-\bar{y}_{r k}, \max _{j}\left\{\bar{y}_{r j}\right\}-\underline{y}_{r k}\right], \quad r=1,2, \ldots, s .}
\end{aligned}
$$

Obviously, $\underline{R}_{i k}^{-}, \bar{R}_{i k}^{-}, \underline{R}_{r k}^{+}, \bar{R}_{r k}^{+} \geq 0$.

Therefore, the MSBM model for evaluating $\mathrm{DMU}_{k}$ with interval data is

$$
\begin{array}{ll}
\min & \rho_{k}=\frac{1-\sum_{i=1}^{m} w_{i}\left[\underline{s}_{i k}^{-}, \bar{s}_{i k}^{-}\right] /\left[\underline{R}_{i k}^{-}, \bar{R}_{i k}^{-}\right]}{1+\sum_{r=1}^{s} v_{r}\left[\underline{s}_{r k}^{+}, \bar{s}_{r k}^{+}\right] /\left[\underline{R}_{r k}^{+}, \bar{R}_{r k}^{+}\right]}, \\
\text {subject to } \begin{cases}{\left[\underline{x}_{i k}, \bar{x}_{i k}\right]=\sum_{j=1}^{n}\left[\underline{x}_{i j}, \bar{x}_{i j}\right] \lambda_{j}+\left[\underline{s}_{i k}^{-}, \bar{s}_{i k}^{-}\right],} & i=1,2, \ldots, m, \\
{\left[\underline{y}_{r k}, \bar{y}_{r k}\right]=\sum_{j=1}^{n}\left[\underline{y}_{r j}, \bar{y}_{r j}\right] \lambda_{j}-\left[\underline{s}_{r k}^{+}, \bar{s}_{r k}^{+}\right],} & r=1,2, \ldots, s, \\
\sum_{j=1}^{n} \lambda_{j}=1, & j=1,2, \ldots, n, \\
\underline{s}_{i k}^{-}, \bar{s}_{i k}^{-}, \underline{s}_{r k}^{+}, \bar{s}_{r k}^{+}, \lambda_{j} \geq 0, & \end{cases}
\end{array}
$$

where $\rho_{k}$ is interval data denoted as $\left[\underline{\rho}_{k}, \bar{\rho}_{k}\right]$. Similarly, when $\underline{R}_{i k}^{-}\left(\bar{R}_{i k}^{-}\right)$or $\underline{R}_{r k}^{+}\left(\bar{R}_{r k}^{+}\right)$is zero, the corresponding term is assumed to be dropped from the numerator or denominator.

The lower bound of the interval efficiency $\rho_{k}$ is the efficiency under the most unfavourable situation for $\mathrm{DMU}_{k}$. In this manner, $\mathrm{DMU}_{k}$ consumes $\bar{x}_{i k}$ to produce $y_{r k}$ while the $\mathrm{DMU}_{j}$ consumes $\underline{x}_{i j}$ to produce $\bar{y}_{r j}(j \neq k)$. Symmetrically, the upper bound of the efficiency $\bar{\rho}_{k}$ is the most favourable situation for $\mathrm{DMU}_{k}$. In this manner, $\mathrm{DMU}_{k}$ consumes $\underline{x}_{i k}$ to produce $\bar{y}_{r k}$ while DMU $\mathrm{DM}_{j}$ consumes $\bar{x}_{i j}$ to produce $\underline{y}_{r j}(j \neq k)$. Therefore, model (5) can be replaced by a pair of precise models as follows: 


$$
\begin{aligned}
& \min \quad \underline{\rho}_{k}=\frac{1-\sum_{i=1}^{m}\left(w_{i} \bar{s}_{i k}^{-}\right) / \bar{R}_{i k}^{-}}{1+\sum_{r=1}^{s}\left(v_{r} \bar{s}_{r k}^{+}\right) / \bar{R}_{r k}^{+}}, \\
& \text {subject to } \begin{cases}\bar{x}_{i k}=\sum_{j=1, j \neq k}^{n} \underline{x}_{i j} \lambda_{j}+\bar{x}_{i k} \lambda_{k}+\bar{s}_{i k}^{-}, & i=1,2, \ldots, m, \\
\underline{y}_{r k}=\sum_{j=1, j \neq k}^{n} \bar{y}_{r j} \lambda_{j}+\underline{y}_{r k} \lambda_{k}-\bar{s}_{r k}^{+}, & r=1,2, \ldots, s, \\
\sum_{j=1}^{n} \lambda_{j}=1, & j=1,2, \ldots, n, \\
\bar{s}_{i k}^{-}, \bar{s}_{r k}^{+}, \lambda_{j} \geq 0, & \end{cases} \\
& \min \quad \bar{\rho}_{k}=\frac{1-\sum_{i=1}^{m}\left(w_{i} \underline{s}_{i k}^{-}\right) / \underline{R}_{i k}^{-}}{1+\sum_{r=1}^{s}\left(v_{r} \underline{s}_{r k}^{+}\right) / \underline{R}_{r k}^{+}}, \\
& \text {subject to } \begin{cases}\underline{x}_{i k}=\sum_{j=1, j \neq k}^{n} \bar{x}_{i j} \lambda_{j}+\underline{x}_{i k} \lambda_{k}+\underline{s}_{i k}^{-}, & i=1,2, \ldots, m, \\
\bar{y}_{r k}=\sum_{j=1, j \neq k}^{n} \underline{y}_{r j} \lambda_{j}+\bar{y}_{r k} \lambda_{k}-\underline{s}_{r k}^{+}, & r=1,2, \ldots, s, \\
\sum_{j=1}^{n} \lambda_{j}=1, & j=1,2, \ldots, n, \\
\underline{s}_{i k}^{-}, \underline{s}_{r k}^{+}, \lambda_{j} \geq 0 . & \end{cases}
\end{aligned}
$$

The IMSBM model can be transformed into a linear programming form by Charnes-Cooper transformation [28]. Considering multiplying a scalar variable $t(t>0)$ to both the numerator and the denominator of the objective function of (8), it does not impact $\underline{\rho}_{k}$. Adjust $t$ and equal the denominator to 1 ; then, the denominator can be regarded as a constraint and the objective function is minimizing the corresponding numerator. The lower bound of the IMSBM model is

$$
\begin{array}{ll}
\min & \underline{\tau}_{k}=t-\sum_{i=1}^{m} \frac{w_{i} t \bar{s}_{i k}^{-}}{\bar{R}_{i k}^{-}}, \\
\text {subject to } \begin{cases}1=t+\sum_{r=1}^{s} \frac{v_{r} t \bar{s}_{r k}^{+}}{\bar{R}_{r k}^{+}}, \\
t \bar{x}_{i k}=\sum_{j=1, j \neq k}^{n} \underline{x}_{i j} t \lambda_{j}+\bar{x}_{i k} t \lambda_{k}+t \bar{s}_{i k}^{-}, & i=1,2, \ldots, m, \\
\underline{y}_{r k}=\sum_{j=1, j \neq k}^{n} \bar{y}_{r j} t \lambda_{j}+\underline{y}_{r k} t \lambda_{k}-t \bar{s}_{r k}^{+}, & r=1,2, \ldots, s, \\
\sum_{j=1}^{n} t \lambda_{j}=t, & j=1,2, \ldots, n, \\
\bar{s}_{i k}^{-}, \bar{s}_{r k}^{+}, \lambda_{j} \geq 0 .\end{cases}
\end{array}
$$


(11) is a nonlinear programming problem due to the nonlinear terms, and some definitions are needed to transform it into a linear programming problem. Assume

$$
\begin{aligned}
\bar{S}_{i k}^{-} & =t \bar{s}_{i k}^{-}, \\
\bar{S}_{r k}^{+} & =t \bar{s}_{r k}^{+}, \\
\Lambda_{j} & =t \lambda_{j} .
\end{aligned}
$$

Obviously, $\bar{S}_{i k}^{-}, \bar{S}_{r k}^{+}, \Lambda_{j} \geq 0$ and the transformed problem is $\min$

$$
\underline{\tau}_{k}=t-\sum_{i=1}^{m} \frac{w_{i} \bar{S}_{i k}^{-}}{\bar{R}_{i k}^{-}}
$$

$$
\text { subject to } \begin{cases}1=t+\sum_{r=1}^{s} \frac{v_{r} \bar{S}_{r k}^{+}}{\bar{R}_{r k}^{+}}, & \\ t \bar{x}_{i k}=\sum_{j=1, j \neq k}^{n} \underline{x}_{i j} \Lambda_{j}+\bar{x}_{i k} \Lambda_{k}+\bar{S}_{i k}^{-}, & i=1,2, \ldots, m, \\ t \underline{y}_{r k}=\sum_{j=1, j \neq k}^{n} \bar{y}_{r j} \Lambda_{j}+\underline{y}_{r k} \Lambda_{k}-\bar{S}_{r k}^{+}, & r=1,2, \ldots, s, \\ \sum_{j=1}^{n} \Lambda_{j}=t, & \\ \bar{S}_{i k}^{-}, \bar{S}_{r k}^{+}, \Lambda_{j} \geq 0 . & \end{cases}
$$

Assuming the optimal solution of (14) is $\left(\underline{\tau}_{k}^{*}, t^{*}, \Lambda^{*}, \bar{S}_{i k}^{-*}, \bar{S}_{r k}^{+*}\right)$, then the optimal solution of (8) is

$$
\begin{gathered}
\underline{\rho}_{k}^{*}=\underline{\tau}_{k}^{*}, \\
\lambda^{*}=\frac{\Lambda^{*}}{t^{*}}, \\
\bar{s}_{i k}^{*}=\frac{\bar{S}_{i k}^{-*}}{t^{*}}, \\
\bar{s}_{r k}^{+*}=\frac{\bar{S}_{r k}^{+*}}{t^{*}} .
\end{gathered}
$$

Symmetrically, the transformed problem of (10) is

$$
\begin{array}{ll}
\min & \bar{\tau}_{k}=t-\sum_{i=1}^{m} \frac{w_{i} \underline{S}_{i k}^{-}}{\underline{R}_{i k}^{-}}, \\
\text {subject to } \begin{cases}t \underline{x}_{i k}=\sum_{j=1, j \neq k}^{n} \bar{x}_{i j} \Lambda_{j}+\underline{x}_{i k} \Lambda_{k}+\underline{S}_{i k}^{-}, & i=1,2, \ldots, m, \\
t \bar{y}_{r k}=\sum_{j=1, j \neq k}^{n} \underline{y}_{r j} \Lambda_{j}+\bar{y}_{r k} \Lambda_{k}-\underline{S}_{r k}^{+}, & r=1,2, \ldots, s, \\
\sum_{j=1}^{n} \Lambda_{j}=t, & j=1,2, \ldots, n, \\
\underline{S}_{i k}^{-}, \underline{S}_{r k}^{+}, \Lambda_{j} \geq 0 . & \end{cases}
\end{array}
$$

Assuming the optimal solution of (17) is $\left(\bar{\tau}_{k}^{*}, t^{*}, \Lambda^{*}\right.$, $\left.\underline{S}_{i k}^{-*}, \underline{S}_{r k}^{+*}\right)$, then the optimal solution of $(10)$ is

$$
\begin{aligned}
\bar{\rho}_{k}^{*} & =\bar{\tau}_{k}^{*}, \\
\lambda^{*} & =\frac{\Lambda^{*}}{t^{*}}, \\
\underline{s}_{i k}^{-*} & =\frac{S_{i k}^{-*}}{t^{*}}, \\
\underline{s}_{r k}^{+*} & =\frac{S_{r k}^{+*}}{t^{*}} .
\end{aligned}
$$

If the lower bound of $\mathrm{DMU}_{k}$ is inefficient, it can be improved to be efficient by

$$
\begin{aligned}
& \bar{x}_{i k} \longleftarrow \bar{x}_{i k}-\bar{s}_{i k}^{-*}, \quad i=1,2, \ldots, m, \\
& \underline{y}_{r k} \longleftarrow \underline{y}_{r k}+\bar{s}_{r k}^{+*}, \quad r=1,2, \ldots, s .
\end{aligned}
$$

Symmetrically, if the upper bound of $\mathrm{DMU}_{k}$ is inefficient, it can be improved to be efficient by

$$
\begin{aligned}
& \underline{x}_{i k} \longleftarrow \underline{x}_{i k}-\underline{s}_{i k}^{-*}, \quad i=1,2, \ldots, m, \\
& \bar{y}_{r k} \longleftarrow \bar{y}_{r k}+\underline{s}_{r k}^{+*}, \quad r=1,2, \ldots, s .
\end{aligned}
$$

2.3. Properties of IMSBM. The following properties are considered as basic in designing an efficiency measure:

P1: Units Invariant. It is considered to be an important property in DEA, and the term in general mathematical properties is known as dimensionless.

P2: Monotone. The measure is monotone decreasing with the increasing of inputs or the decreasing of outputs.

P3: Translation Invariant. It is critical, especially when input-output data contain zero or negative values.

IMSBM model is demonstrated to possess these properties in the following.

Theorem 1. IMSBM model is units invariant.

Proof. Considering the $g^{\text {th }}$ input and $h^{\text {th }}$ output in the model (8), rescale both bounds of the $g^{\text {th }}$ input by multiplying it a scalar $\alpha>0$ and rescale both bounds of the $h^{\text {th }}$ output by multiplying it a scalar $\beta>0$. The ideal point is $I_{\alpha, \beta}=$ $\left(\min _{j} \underline{x}_{i j}(i=1,2, \ldots, m, i \neq g), \min _{j}\left(\alpha \underline{x}_{g j}\right), \max _{j} \bar{y}_{r j}(r=1\right.$, $\left.2, \ldots, s, r \neq h), \max _{j}\left(\beta \bar{y}_{h j}\right)\right)$. It can be proved that $\bar{R}_{i k, \alpha}^{-}=\bar{R}_{i k}^{-}(i \neq g), \quad \bar{R}_{g k, \alpha}^{-}=\alpha \bar{R}_{g k}^{-}, \quad \bar{R}_{r k, \beta}^{+}=\bar{R}_{r k}^{+}(r \neq h), \quad$ and $\bar{R}_{h k, \beta}^{+}=\beta \bar{R}_{h k}^{+}$. From the constraints, we have $\bar{s}_{i k, \alpha}^{-}=\bar{s}_{i k}^{-}(i \neq g)$, $\bar{s}_{g k, \alpha}^{-}=\alpha \bar{s}_{g k}^{-}, \bar{s}_{r k, \beta}^{+}=\bar{s}_{r k}^{+}(r \neq h)$, and $\bar{s}_{h k, \beta}^{+}=\beta \bar{s}_{h k}^{+}$. The rescaling does not impact $\rho_{k}$. Thus, model (8) is units invariant.

Model (10) can be proved likewise. Therefore, the IMSBM model is units invariant. This proof is complete.

Theorem 2. IMSBM model is monotone.

Proof. Both bounds of the $i^{\text {th }}$ input of $\mathrm{DMU}_{k}$ are increased by $\Delta x_{i k}$, i.e., $\underline{x}_{i k} \longrightarrow \underline{x}_{i k}+\Delta x_{i k}$ and $\bar{x}_{i k} \longrightarrow \bar{x}_{i k}+\Delta x_{i k}$, and 
both bounds of the $r^{\text {th }}$ output of $\mathrm{DMU}_{k}$ are decreased by $\Delta y_{r k}$, i.e., $\underline{y}_{r k} \longrightarrow \underline{y}_{r k}-\Delta y_{r k}$ and $\bar{y}_{r k} \longrightarrow \bar{y}_{r k}-\Delta y_{r k}$. Then, $\bar{R}_{i k}^{\prime \prime}=\bar{x}_{i k}+\Delta x_{i k}-\min \left\{\underline{x}_{i j}(j \neq k), \underline{x}_{i k}+\Delta x_{i k}\right\}$ and $\bar{R}_{r k}^{+\prime}=$ $\max \left\{\bar{y}_{r j}(j \neq k), \bar{y}_{r k}-\Delta y_{r k}\right\}-\left(\underline{y}_{r k}-\Delta y_{r k}\right)$. The slacks of inputs and outputs change into $\bar{s}_{i k}^{-\prime}=\bar{x}_{i k}+\Delta x_{i k}-$ $\sum_{j=1, j \neq k}^{n} \lambda_{j} \underline{x}_{i j}-\lambda_{k}\left(\bar{x}_{i k}+\Delta x_{i k}\right) \quad$ and $\quad \bar{s}_{r k}^{+\prime}=\sum_{j=1, j \neq k}^{n} \lambda_{j} \bar{y}_{r j}+$ $\lambda_{k}\left(y_{r k}-\Delta y_{r k}\right)-\left(y_{r k}-\Delta y_{r k}\right)$. Proving $\rho_{k}$ is monotone can be converted into two problems: (1) the numerator of the objective function is a decreasing function of $\Delta x_{i k}$ and (2) the denominator of the objective function is an increasing function of $\Delta y_{r k}$.

Firstly, we prove that the numerator of the objective function is a decreasing function of $\Delta x_{i k}$. There are two cases for $\bar{R}_{i k}^{\prime}$ :

(1) If $\forall j \neq k$ such that $\underline{x}_{i j} \geq \underline{x}_{i k}+\Delta x_{i k}$, then $\bar{R}_{i k}^{\prime \prime}=\bar{x}_{i k}+$ $\Delta x_{i k}-\left(\underline{x}_{i k}+\Delta x_{i k}\right)=\bar{x}_{i k}-\underline{x}_{i k}$. It can be proved that $\left(\left(\mathrm{d}\left(1-\sum_{i=1}^{m} w_{i} \bar{s}_{i k}^{\prime} / \bar{R}_{i k}^{-\prime}\right)\right) /\left(\mathrm{d}\left(\Delta x_{i k}\right)\right)\right) \leq 0$. Therefore, in this case, the numerator is a decreasing function of $\Delta x_{i k}$

(2) If $\exists j \neq k$ such that $\underline{x}_{i j} \leq \underline{x}_{i k}+\Delta x_{i k}$, then $\bar{R}_{i k}^{-\prime}=$ $\bar{x}_{i k}+\Delta x_{i k}-\min _{j \neq k}\left\{\underline{x}_{i j}\right\}$. It can be proved that $\left(\left(\mathrm{d}\left(1-\sum_{i=1}^{m}\left(w_{i} \bar{s}_{i k}^{\prime \prime}\right) /\left(\bar{R}_{i k}^{-\prime}\right)\right)\right) /\left(\mathrm{d}\left(\Delta x_{i k}\right)\right)\right) \leq 0$. Therefore, in this case, the numerator is a decreasing function of $\Delta x_{i k}$;

In conclusion, the numerator of the objective function is a decreasing function of $\Delta x_{i k}$.

Then, we prove that the denominator of the objective function is an increasing function of $\Delta y_{r k}$. There are two cases for $\bar{R}_{r k}^{+\prime}$ :

(1) If $\forall \mathrm{j} \neq \mathrm{k}$ such that $\bar{y}_{r j} \leq \bar{y}_{r k}-\Delta y_{r k}$, then $\bar{R}_{r k}^{+}=\bar{y}_{r k}-$ $\Delta y_{r k}-\left(\underline{y}_{r k}-\Delta y_{r k}\right)=\bar{y}_{r k}-\underline{y}_{r k}$. It can be proved that $\quad\left(\left(\mathrm{d}\left(1+\sum_{r=1}^{s}\left(v_{r} \bar{s}_{r k}^{+\prime}\right) /\left(\bar{R}_{r k}^{+\prime}\right)\right)\right) /\left(\mathrm{d}\left(\Delta y_{r k}\right)\right)\right) \geq 0$. Therefore, in this case, the denominator is an increasing function of $\Delta y_{r k}$.

(2) If $\exists j \neq k$ such that $\bar{y}_{r j} \geq \bar{y}_{r k}-\Delta y_{r k}$, then $\bar{R}_{r k}^{+\prime}=$ $\max _{j \neq k}\left\{\bar{y}_{r j}\right\}-\left(\underline{y}_{r k}-\Delta y_{r k}\right)$. It can be proved that $\left(\left(\mathrm{d}\left(1+\sum_{r=1}^{s}\left(v_{r} \bar{s}_{r k}^{\prime}\right) / \bar{R}_{r k}^{+\prime}\right)\right) /\left(\mathrm{d}\left(\Delta y_{r k}\right)\right)\right) \geq 0$. Therefore, in this case, the denominator is an increasing function of $\Delta y_{r k}$.

In conclusion, the denominator of the objective function is an increasing function of $\Delta y_{r k}$.

In conclusion, model (8) is monotone decreasing with the increasing of inputs or the decreasing of outputs.

Likewise, model (10) can also be verified to be monotone decreasing with the increasing of inputs or the decreasing of outputs. Therefore, the IMSBM model is monotone. This proof is complete.

\section{Theorem 3. IMSBM model is translation invariant.}

Proof. A measure is translation invariant if and only if the model is equivalent before and after the translation [29].

Transform the input data $\underline{x}_{i j}$ and $\bar{x}_{i j}(i=1,2, \ldots, m)$ by the real number $z_{i}(i=1,2, \ldots, m)$ and transform the output data $\underline{y}_{r j}$ and $\bar{y}_{r j}(r=1,2, \ldots, s)$ by the real number $t_{r}(r=1$, $2, \ldots, s)$, where $z_{i}$ subjects to $\underline{x}_{i j}+z_{i} \geq 0(\forall j=1,2, \ldots, n)$ and $t_{r}$ subjects to $y_{r j}+t_{r} \geq 0(\forall j=1,2, \ldots, n)$ (without loss of generality, $z_{i}$ and $t_{r}$ are assumed to be nonnegative). The model of translated data is

$$
\begin{array}{ll}
\min & \underline{\rho}_{k}^{\prime}=\frac{1-\sum_{i=1}^{m}\left(w_{i} \bar{s}_{i k}^{-\prime}\right) / \bar{R}_{i k}^{-\prime}}{1+\sum_{r=1}^{s}\left(v_{r} \bar{s}_{r k}^{+\prime}\right) / \bar{R}_{r k}^{+\prime}}, \\
\text { subject to } \begin{cases}\bar{x}_{i k}^{\prime}=\sum_{j=1, j \neq k}^{n} \underline{x}_{i j}^{\prime} \lambda_{j}+\bar{x}_{i k}^{\prime} \lambda_{k}+\bar{s}_{i k}^{\prime \prime}, & i=1,2, \ldots, m, \\
\underline{y}_{r k}^{\prime}=\sum_{j=1, j \neq k}^{n} \bar{y}_{r j}^{\prime} \lambda_{j}+\underline{y}_{r k}^{\prime} \lambda_{k}-\widetilde{s}_{r k}^{+}, & r=1,2, \ldots, s, \\
\sum_{j=1}^{n} \lambda_{j}=1, & j=1,2, \ldots, n, \\
\sum_{i=1}^{m} w_{i}=1, \sum_{r=1}^{s} v_{r}=1, & \\
w_{i}, v_{r}, \widetilde{s}_{i k}^{-\prime}, \widetilde{s}_{r k}^{+\prime}, \lambda_{j} \geq 0,\end{cases}
\end{array}
$$

where $\underline{x}_{i j}^{\prime}=\underline{x}_{i j}+z_{i}, \bar{x}_{i k}^{\prime}=\bar{x}_{i k}+z_{i}, \underline{y}_{r j}^{\prime}=\underline{y}_{r j}+t_{r}$, and $\bar{y}_{r j}^{\prime}=$ $\bar{y}_{r j}+t_{r}$. It can be verified that $\bar{R}_{i k}^{-\prime}=\bar{R}_{i k}^{-}$and $\bar{R}_{r k}^{+\prime}=\bar{R}_{r k}^{+}$. Since $\sum_{j=1}^{n} \lambda_{j}=1$, the constraints of (22) implicate $\bar{s}_{i k}^{-\prime}=\bar{s}_{i k}^{-}$and $\bar{s}_{r k}^{+\prime}=\bar{s}_{r k}^{+}$. Thus, model (8) and model (22) are equivalent problems. Therefore, model (8) is translation invariant.

Model (10) can be proved to be translation invariant likewise. Therefore, the IMSBM model is translation invariant. This proof is complete.

In the following part, let us demonstrate that the efficiency score of the IMSBM model is in the range of $[0,1]$.

Note, since $\sum_{j=1}^{n} \lambda_{j}=1$,

$$
\begin{aligned}
& 0 \leq \bar{s}_{i k}^{-}=\bar{x}_{i k}-\sum_{j=1, j \neq k}^{n} \underline{x}_{i j} \lambda_{j}-\bar{x}_{i k} \lambda_{k} \leq \bar{x}_{i k}-\min _{j}\left\{\underline{x}_{i j}\right\}=\bar{R}_{i k}^{-}, \\
& 0 \leq \bar{s}_{r k}^{+}=\sum_{j=1, j \neq k}^{n} \bar{y}_{r j} \lambda_{j}+\underline{y}_{r k} \lambda_{j}-\underline{y}_{r k} \leq \max _{j}\left\{\bar{y}_{r j}\right\}-\underline{y}_{r k}=\bar{R}_{r k}^{+}, \\
& 0 \leq \underline{s}_{i k}^{-}=\underline{x}_{i k}-\sum_{j=1, j \neq k}^{n} \bar{x}_{i j} \lambda_{j}-\underline{x}_{i k} \lambda_{k} \leq \underline{x}_{i k}-\min _{j}\left\{\underline{x}_{i j}\right\}=\underline{R}_{i k}^{-}, \\
& 0 \leq \underline{s}_{r k}^{+}=\sum_{j=1, j \neq k}^{n} \underline{y}_{r j} \lambda_{j}+\bar{y}_{r k} \lambda_{j}-\bar{y}_{r k} \leq \max _{j}\left\{\bar{y}_{r j}\right\}-\bar{y}_{r k}=\underline{R}_{r k}^{+} .
\end{aligned}
$$

With $\sum_{i=1}^{m} w_{i} \leq 1$ and $\sum_{r=1}^{s} v_{r} \leq 1$ (it is not greater than 1 because the corresponding terms are dropped when $\underline{R}_{i k}^{-}$ $\left(\bar{R}_{i k}^{-}\right)$and $\underline{R}_{r k}^{+}\left(\bar{R}_{r k}^{+}\right)$are zero), the lower bound and upper bound of the efficiency score can be verified to be $0 \leq \rho_{k} \leq 1$ and $0 \leq \bar{\rho}_{k} \leq 1$ (even if the input-output data are negative).

Since $\rho_{k}$ is obtained in the most unfavourable situation of $\mathrm{DMU}_{k}$ and $\bar{\rho}_{k}$ is obtained in the most favourable situation, the interval efficiency score satisfies $0 \leq \underline{\rho}_{k} \leq \bar{\rho}_{k} \leq 1$. 
2.4. Advantages and Benefits of IMSBM. To demonstrate the advantages over the existing models, we compared the IMSBM model with the IGDEA model [7], the interval SBM model [16] (Azizi et al. [16] did not specifically name their proposed model; for our convenience, we mentioned it as the interval SBM model in the comparison), the VRM model and its variants $[19,21]$ (for our convenience, we mentioned them as the VRMs in the comparison), the MSBM model [22], and the interval SORM model [24].

Table 1 shows that the IMSBM model, as an interval model, can easily tackle the imprecise data without losing the information besides the situation complexity. Further, it has the advantage of handling the negative values in the data without any data transformation. At last, due to the slacksbased characteristics, the IMSBM model has the ability to reveal the inefficiency caused by both radial and nonradial slacks.

Applicability of DEA models on imprecise data extends its effectiveness for real-life situations. As imprecise data contain more information, IMSBM could be applied directly to measure the relative efficiency. The interval efficiency calculated by the IMSBM model reflects the performance of the observed DMU in the most unfavourable and most favourable situations. The lower bound of the interval efficiency indicates the most unfavourable situation when the observed DMU consumes the upper bound of inputs to produce the lower bound of outputs while other DMUs consume the lower bound of inputs to produce the upper bound of outputs, and the upper bound of the interval efficiency indicates the most favourable situation when the observed DMU consumes the lower bound of inputs to produce the upper bound of the outputs while the others consume the upper bound of inputs to produce the lower bound of outputs.

It is important to mention that the IMSBM model is constructed without any prior assumption of nonnegative data. As an efficiency measure, the IMSBM model is units invariant, monotone, and translation invariant. With the translation invariance property, the IMSBM model can evaluate the efficiency of a particular DMU containing negative or zero value in the input-output data without any prior data transformation. This property ensures the effectiveness of the IMSBM model application in the existence of negative data.

The IMSBM model puts aside the assumption of proportionate changes in inputs and outputs and deals with slacks directly. Although interval SBM models have the same ability, in the existing interval SBM models, translation invariant is not always consistent, and sometimes efficiency scores may be negative when negative inputs or outputs are employed in the evaluation process. However, efficiency measured by the IMSBM model always ranges from 0 to 1 , even with the existence of negative data.

\section{Classification and the Ranking of the DMUs}

Since the efficiency score measured by the IMSBM model is calculated in an interval form, a simple and practical
TABle 1: Comparing IMSBM model with other DEA models.

\begin{tabular}{lcccccc}
\hline & IGDEA & $\begin{array}{c}\text { Interval } \\
\text { SBM }\end{array}$ & VRMs & MSBM & $\begin{array}{c}\text { Interval } \\
\text { SORM }\end{array}$ & IMSBM \\
\hline $\begin{array}{l}\text { Interval } \\
\text { data }\end{array}$ & $\sqrt{ }$ & $\sqrt{ }$ & $\times$ & $\times$ & $\sqrt{ }$ & $\sqrt{ }$ \\
$\begin{array}{l}\text { Negative } \\
\text { data }\end{array}$ & $\times$ & $\times$ & $\sqrt{ }$ & $\sqrt{ }$ & $\sqrt{ }$ & $\sqrt{ }$ \\
$\begin{array}{l}\text { Slacks- } \\
\text { based }\end{array}$ & $\times$ & $\sqrt{ }$ & $\times$ & $\sqrt{ }$ & $\times$ & $\sqrt{ }$ \\
\hline
\end{tabular}

approach is needed for comparing and ranking the performance of the DMUs.

Firstly, the DMUs are classified into three subsets according to the interval efficiency (see $[4,15,24]$ ):

(1) The strictly efficient subset is $E^{++}=\left\{\mathrm{DMU}_{j}\right.$, $\left.j=1,2, \ldots, n \mid \underline{\rho}_{j}=1, \bar{\rho}_{k}=1\right\}$ : both the lower and upper bounds of the interval efficiency score are equal to 1 , indicating the observed DMU performs efficiently no matter in the most unfavourable or most favourable situation.

(2) The weakly efficient subset is $E^{+}=\left\{\mathrm{DMU}_{j}, j=1\right.$, $\left.2, \ldots, n \mid \underline{\rho}_{j}<1, \bar{\rho}_{k}=1\right\}$ : the lower bound of the interval efficiency score is less than 1 and the upper bound of the interval efficiency is equal to 1 , indicating the observed DMU performs efficiently only in the most favourable situation.

(3) The inefficient subset is $E^{-}=\left\{\mathrm{DMU}_{j}, j=1\right.$, $\left.2, \ldots, n \mid \underline{\rho}_{j}<1, \bar{\rho}_{k}<1\right\}$ : both the lower and upper bounds of the interval efficiency score are less than 1 , indicating the observed DMU performs inefficiently in the most unfavourable and most favourable situation.

Obviously, in complex systems, each subset contains more than one DMU. In addition to the classification, a ranking approach is needed in the last two subsets. Wang et al. [30] proposed the degree of preference approach to rank interval data by a matrix.

Suppose there are two interval efficiency denoted as $\rho_{k_{1}}=$ $\left[\underline{\rho}_{k_{1}}, \bar{\rho}_{k_{1}}\right]$ and $\rho_{k_{2}}=\left[\underline{\rho}_{k_{2}}, \bar{\rho}_{k_{2}}\right]$, then the degree of preference of $\rho_{k_{1}}$ over $\rho_{k_{2}}\left(\rho_{k_{1}}>\rho_{k_{2}}\right)^{2}$ can be defined as

$$
P\left(\rho_{k_{1}}>\rho_{k_{2}}\right)=\frac{\max \left(0, \bar{\rho}_{k_{1}}-\underline{\rho}_{k_{2}}\right)-\max \left(0, \underline{\rho}_{k_{1}}-\bar{\rho}_{k_{2}}\right)}{\left(\bar{\rho}_{k_{1}}-\underline{\rho}_{k_{1}}\right)+\left(\bar{\rho}_{k_{2}}-\underline{\rho}_{k_{2}}\right)} .
$$

Symmetrically, the degree of preference of $\rho_{k_{2}}$ over $\rho_{k_{1}}$ $\left(\rho_{k_{2}}>\rho_{k_{1}}\right)$ can be defined as

$$
P\left(\rho_{k_{2}}>\rho_{k_{1}}\right)=\frac{\max \left(0, \bar{\rho}_{k_{2}}-\underline{\underline{\rho_{k_{1}}}}\right)-\max \left(0, \underline{\rho}_{k_{2}}-\bar{\rho}_{k_{1}}\right)}{\left(\bar{\rho}_{k_{1}}-\underline{\rho}_{k_{1}}\right)+\left(\bar{\rho}_{k_{2}}-\underline{\rho}_{k_{2}}\right)} .
$$

It is easy to prove $P\left(\rho_{k_{1}}>\rho_{k_{2}}\right)+P\left(\rho_{k_{2}}>\rho_{k_{1}}\right)=1$ and $P\left(\rho_{k_{1}}>\rho_{k_{2}}\right)=P\left(\rho_{k_{2}}>\rho_{k_{1}}\right)=0.5$ when $\rho_{k_{1}}=\rho_{k_{2}}$. 
If $P\left(\rho_{k_{1}}>\rho_{k_{2}}\right)>P\left(\rho_{k_{2}}>\rho_{k_{1}}\right)$, then $\rho_{k_{1}}$ is superior to $\rho_{k_{2}}$, denoted as $\rho_{k_{1}}>\rho_{k_{2}}$; if $P\left(\rho_{k_{1}}>\rho_{k_{2}}\right)=P\left(\rho_{k_{2}}>\rho_{k_{1}}\right)=0.5$, then $\rho_{k_{1}}$ is indifferent with $\rho_{k_{2}}$, denoted as $\rho_{k_{1}} \sim \rho_{k_{2}}$; if $P\left(\rho_{k_{1}}>\right.$ $\left.\rho_{k_{2}}\right)<P\left(\rho_{k_{2}}>\rho_{k_{1}}\right)$, then $\rho_{k_{1}}$ is inferior to $\rho_{k_{2}}$, denoted as $\rho_{k_{1}} \prec \rho_{k_{2}}$.

It can be verified if $P\left(\rho_{k_{2}}>\rho_{k_{1}}\right) \geq 0.5$ and $P\left(\rho_{k_{3}}>\right.$ $\left.\rho_{k_{2}}\right) \geq 0.5$, then $P\left(\rho_{k_{3}}>\rho_{k_{1}}\right) \geq 0.5$, indicating the degree of preference satisfies transitivity.

The ranking progress is outlined as follows:

Step 1: calculate a $n \times n$ matrix of the degree of preference to reflect the interrelationship among DMUs:

$$
M_{p}=\left[\begin{array}{cccc}
- & p_{12} & \ldots & p_{1 n} \\
p_{21} & - & \ldots & p_{2 n} \\
\vdots & \vdots & \vdots & \vdots \\
p_{n 1} & p_{n 2} & \ldots & -
\end{array}\right],
$$

where

$$
p_{k_{1} k_{2}}=P\left(\rho_{k_{1}}>\rho_{k_{2}}\right), \quad k_{1}, k_{2}=1,2, \ldots, n, k_{1} \neq k_{2} .
$$

Step 2: find out a row in which all of the elements except the diagonal one are not less than 0.5. The corresponding $\mathrm{DMU}_{k}$ is regarded as the strongest performing one within the remaining DMUs.

Step 3: remove the $k^{\text {th }}$ row and $k^{\text {th }}$ column from the matrix.

Step 4: repeat step 2 and step 3 in the reduced matrix until only one DMU remains.

Property 1. There is a row in the matrix of the degree of preference in which all of the elements except the diagonal one are not less than 0.5 .

Proof. or a $2 \times 2$ matrix, since $p_{12}+p_{21}=1$, the property is possessed.

Suppose that for a $(n-1) \times(n-1)(n \geq 3)$ matrix, the property is possessed. Without loss of generality, we assume in the first row, all of the elements except $p_{11}$ are not less than 0.5 , i.e., $p_{1 j} \geq 0.5, j=2, \ldots,(n-1)$. Now, based on the $(n-1) \times(n-1)$ matrix, a $n \times n$ matrix is constructed by attaching $p_{n j}, j=1,2, \ldots,(n-1)$ to the last row and $p_{j n}, j=1,2, \ldots,(n-1)$ to the last column.

If $p_{1 n} \geq 0.5$, then $p_{1 j} \geq 0.5, j=2, \ldots, n$. Thus, in the $1^{s t}$ row of the $n \times n$ matrix, all of the elements except $p_{11}$ are not less than 0.5 .

Otherwise, if $p_{1 n}<0.5$, since $p_{1 n}+p_{n 1}=1$, then $p_{n 1}>0.5$. On the other hand, with the assumption of $p_{1 j} \geq 0.5, j=2, \ldots,(n-1)$, we have $p_{n j} \geq 0.5, j=2, \ldots$, $(n-1)$ due to the transitivity. Thus, $p_{n j} \geq 0.5, j=1$, $2, \ldots,(n-1)$. Therefore, in the $n^{\text {th }}$ row of the $n \times n$ matrix, all of the elements except $p_{n n}$ are not less than 0.5.

This proof is complete.

\section{Numerical Illustration}

To demonstrate the proposed IMSBM model, we use banking DMUs with positive and negative interval data. For performance evaluation, we used 20 commercial banks operating in the Gulf Cooperation Council (GCC) countries [24]. Table 2 illustrates three input ((1) total assets (ASST), (2) capital (EQTY), and (3) deposits (DEPO)) and two output ((1) loans (LOAN) and (2) profit (PROF)) data of 20 commercial banks.

Table 2 shows the input-output data. According to the available data, some banks have negative profit at both lower and upper bounds (e.g., $\mathrm{DMU}_{9}, \mathrm{DMU}_{11}, \mathrm{DMU}_{18}, \mathrm{DMU}_{19}$, and $\mathrm{DMU}_{20}$ ), some banks have negative profit at their lower bound but positive profit at upper bound (e.g., $\mathrm{DMU}_{1}$ and $\mathrm{DMU}_{12}$ ), and the rest have positive profit at both bounds. Now, the IMSBM model is applied to evaluate the interval efficiency scores of these banks. To simplify the problem, as it is presented in Table 3, the inputs and outputs are weighted equally, respectively.

The interval efficiency scores and the classification of the 20 banks are shown in Table 4 . As a comparison, the interval efficiency scores evaluated by the interval SORM model and the corresponding classification are shown in the last two columns.

Table 4 shows the efficiency scores of all 20 DMUs evaluated by the IMSBM model. $\mathrm{DMU}_{1}, \mathrm{DMU}_{3}, \mathrm{DMU}_{5}$, $\mathrm{DMU}_{7}, \mathrm{DMU}_{9}$, and $\mathrm{DMU}_{20}$ are strictly efficient, $\mathrm{DMU}$, $\mathrm{DMU}_{11}, \mathrm{DMU}_{14}, \mathrm{DMU}_{15}$, and $\mathrm{DMU}_{19}$ are weakly efficient, and the rest of the DMUs are inefficient.

Comparing the efficiency scores calculated by the IMSBM model with the efficiency scores calculated by interval SORM model, it can be seen that strictly efficient DMUs in the IMSBM model are still strictly efficient in interval SORM model (e.g., $\mathrm{DMU}_{1}, \mathrm{DMU}_{3}, \mathrm{DMU}_{5}, \mathrm{DMU}_{7}$, $\mathrm{DMU}_{9}$, and $\mathrm{DMU}_{20}$ ), but strictly efficient DMUs in interval SORM model are not always strictly efficient in IMSBM model (e.g., $\mathrm{DMU}_{15}$ ). The reason behind these results is that the interval SORM model just focuses on radial efficiency while the nonradial inefficiency is ignored, which fails to reflect the inefficiency caused by nonradial slacks. However, the IMSBM model considers the inefficiency caused not only by radial slacks but also by nonradial slacks. Therefore, the efficiency score evaluated by the IMSBM model cannot be greater than the interval SORM model.

In addition to the classification, the detail of the performance ranking is needed. The strictly efficient DMUs are ranked top position and the remaining DMUs are assigned the ranks according to the degree of preference. Table 5 shows the degree of preference among the weakly efficient and inefficient DMUs.

From the degree of preference matrix, the relationship among the weakly efficient and inefficient DMUs is established as $\mathrm{DMU}_{14}>\mathrm{DMU}_{15}>\mathrm{DMU}_{2}>\mathrm{DMU}_{19}>\mathrm{DMU}_{11}>$ $\mathrm{DMU}_{16}>\mathrm{DMU}_{10}>\mathrm{DMU}_{4}>\mathrm{DMU}_{17}>\mathrm{DMU}_{6}>\mathrm{DMU}_{13} \succ$ $\mathrm{DMU}_{18}>\mathrm{DMU}_{12}>\mathrm{DMU}_{8}$. By putting the strictly efficient 
TABLE 2: Input and output data for 20 banks.

\begin{tabular}{lccccc}
\hline & & Inputs & & & Outputs \\
DMU & ASST & EQTY & DEPO & LOAN & {$[-1.4,2.8]$} \\
& {$[285.5,299.3]$} & {$[56.7,64.9]$} & {$[29.5,31.2]$} & {$[214.2,232.7]$} & {$[5357.0,6228.8]$} \\
DMU1 & {$[8522.7,9652.2]$} & {$[1353.9,1450.5]$} & {$[6678.6,7043.1]$} & {$[181.2,205.6]$} \\
DMU2 & {$[2443.6,2494.0]$} & {$[401.1,439.1]$} & {$[1601.1,1615]$} & {$[23.0,26.3]$} \\
DMU3 & {$[4953.0,5352.9]$} & {$[639.9,648.7]$} & {$[4219.3,4383.5]$} & {$[2196.7,2276]$} & {$[72.6,79.0]$} \\
DMU4 & {$[669.5,706.1]$} & {$[78.4,91.6]$} & {$[579.1,584.2]$} & {$[266.2,309.7]$} & {$[19.7,22.8]$} \\
DMU5 & {$[5806.6,6627.4]$} & {$[939.1,1074.5]$} & {$[4318.8,4852.2]$} & {$[2451.5,2470.0]$} & {$[67.2,75.9]$} \\
DMU6 & {$[17844.5,20466.3]$} & {$[2064.1,2281.1]$} & {$[13733.7,14569.9]$} & {$[14457.0,16633.9]$} & {$[415.9,427.6]$} \\
DMU7 & {$[1785.1,1988.5]$} & {$[388.6,450.7]$} & {$[1353.0,1376.4]$} & {$[438.3,481.8]$} & {$[9.0,10.3]$} \\
DMU8 & {$[33141.3,34728.0]$} & {$[1996.6,2234.4]$} & {$[26183.6,28367]$} & {$[17387.5,17945.4]$} & {$[-57.7,-33.8]$} \\
DMU9 & {$[13372.5,14523.3]$} & {$[1071.1,1136.6]$} & {$[11533.6,12718]$} & {$[4834.7,4978.5]$} & {$[173.2,186.8]$} \\
DMU10 & {$[630.7,687.8]$} & {$[115.1,118.7]$} & {$[507.5,531.1]$} & {$[495.5,529.3]$} & {$[-5.8,-5.6]$} \\
DMU11 & {$[654.5,680.7]$} & {$[83.5,89.3]$} & {$[554.8,598.9]$} & {$[334.3,374.7]$} & {$[-15.5,0.8]$} \\
DMU12 & {$[1718.3,1866.8]$} & {$[226.7,237.1]$} & {$[1464.3,1550.3]$} & {$[714.9,783.0]$} & {$[20.0,21.9]$} \\
DMU13 & {$[1011.5,1113.7]$} & {$[139.4,141.8]$} & {$[835.5,867.7]$} & {$[819.2,892.7]$} & {$[23.9,26.8]$} \\
DMU14 & {$[4535.5,5209.8]$} & {$[450.9,467.8]$} & {$[3788.3,4074.1]$} & {$[3604.5,3777.3]$} & {$[67.4,75.1]$} \\
DMU15 & {$[3652.4,4066.2]$} & {$[394.1,407.3]$} & {$[2960.4,3244.5]$} & {$[1614.4,1845.2]$} & {$[58.0,61.7]$} \\
DMU16 & {$[5356.4,6311.2]$} & {$[575.2,609.4]$} & {$[4688.2,4789.6]$} & {$[2298.9,2589.8]$} & {$[42.3,43.7]$} \\
DMU17 & {$[684.0,731.2]$} & {$[129.3,138.7]$} & {$[547.9,607.8]$} & {$[408.6,463.3]$} & {$[-17.7,-17.2]$} \\
DMU18 & {$[2702.5,3074.7]$} & {$[281.7,289.6]$} & {$[2268.7,2623.0]$} & {$[2008.2,2362.5]$} & {$[-0.8,-0.7]$} \\
DMU19 & {$[1007.2,1070.6]$} & {$[75.0,78.3]$} & {$[848.3,975.0]$} & {$[833.4,885.9]$} & {$[-15.3,-13.4]$} \\
DMU20 & & & &
\end{tabular}

TABLE 3: The equal weights of inputs and outputs.

\begin{tabular}{lccccc}
\hline Indicators & $w_{1}$ ASST & $w_{2}$ EQTY & $w_{3}$ DEPO & $v_{1}$ LOAN & $v_{2}$ PROF \\
\hline Weights & 0.333 & 0.333 & 0.333 & 0.5 & 0.5 \\
\hline
\end{tabular}

TABLE 4: Results of the interval efficiency for 20 banks with equal weights.

\begin{tabular}{lcccc}
\hline DMU & IMSBM & Classification & Interval SORM & Classification \\
\hline DMU1 & {$[1,1]$} & $E^{++}$ & {$[1,1]$} & {$[0.813,1]$} \\
DMU2 & {$[0.679,1]$} & $E^{+}$ & {$[1,1]$} & $E^{++}$ \\
DMU3 & {$[1,1]$} & $E^{++}$ & {$[0.520,0.698]$} & $E^{+}$ \\
DMU4 & {$[0.480,0.657]$} & $E^{-}$ & {$[1,1]$} & $E^{++}$ \\
DMU5 & {$[1,1]$} & $E^{++}$ & {$[0.427,0.614]$} & $E^{-}$ \\
DMU6 & {$[0.362,0.538]$} & $E^{-}$ & {$[1,1]$} & $E^{++}$ \\
DMU7 & {$[1,1]$} & $E^{++}$ & {$[0.253,0.513]$} & $E^{-}$ \\
DMU8 & {$[0.116,0.225]$} & $E^{-}$ & {$[1,1]$} & $E^{++}$ \\
DMU9 & {$[1,1]$} & $E^{++}$ & {$[0.718,0.901]$} & $E^{-}$ \\
DMU10 & {$[0.506,0.691]$} & $E^{-}$ & {$[0.667,1]$} & $E^{-}$ \\
DMU11 & {$[0.498,1]$} & $E^{+}$ & {$[0.990,0.633]$} & $E^{+}$ \\
DMU12 & {$[0.195,0.613]$} & $E^{-}$ & {$[1,1]$} & $E^{+}$ \\
DMU13 & {$[0.349,0.521]$} & $E^{-}$ & {$[0.616,0.834]$} & $E^{-}$ \\
DMU14 & {$[0.852,1]$} & $E^{+}$ & {$[0.470,0.665]$} & $E^{+}$ \\
DMU15 & {$[0.787,1]$} & $E^{+}$ & {$[0.614,0.846]$} & $E^{++}$ \\
DMU16 & {$[0.526,0.756]$} & $E^{-}$ & {$[0.866,1]$} & $E^{-}$ \\
DMU17 & {$[0.389,0.609]$} & $E^{-}$ & {$[1,1]$} \\
DMU18 & {$[0.287,0.572]$} & $E^{-}$ & $E^{-}$ \\
DMU19 & {$[0.667,1]$} & $E^{+}$ & $E^{+}$ \\
DMU20 & {$[1,1]$} & $E^{++}$ & $E^{++}$ \\
\hline
\end{tabular}

DMUs in the top position and remaining in the second position, all the DMUs are ranked as shown in Table 6.

With the allowance to alter the input and output weights, we adjust them to illustrate the effect of weights on the efficiency scores. The unequal weights are shown in Table 7.
The interval efficiency scores, classification, and the ranks of the 20 banks with unequal weights are shown in Table 8 . The comparison with the interval SORM model is omitted just because it is not directly relevant at this stage.

Comparing Table 8 with Table 4, we find that adjusting the weights has no impact on the classifications of the 
TABLE 5: Degree of preference matrix for weakly efficient and inefficient banks with equal weights.

\begin{tabular}{lccccccccccccccc}
\hline DMU & 2 & 4 & 6 & 8 & 10 & 11 & 12 & 13 & 14 & 15 & 16 & 17 & 18 & 19 \\
\hline 2 & - & 1 & 1 & 1 & 0.98 & 0.61 & 1 & 1 & 0.32 & 0.40 & 0.86 & 1 & 1 & 0.51 \\
4 & 0 & - & 0.84 & 1 & 0.42 & 0.23 & 0.78 & 0.88 & 0 & 0 & 0.32 & 0.68 & 0.80 & 0 \\
6 & 0 & 0.16 & - & 1 & 0.09 & 0.06 & 0.58 & 0.54 & 0 & 0 & 0.03 & 0.38 & 0.54 & 0 \\
8 & 0 & 0 & 0 & - & 0 & 0 & 0.06 & 0 & 0 & 0 & 0 & 0 & 0 & 0 \\
10 & 0.02 & 0.58 & 0.91 & 1 & - & 0.28 & 0.82 & 0.96 & 0 & 0 & 0.40 & 0.75 & 0.86 & 0.05 \\
11 & 0.39 & 0.77 & 0.94 & 1 & 0.72 & - & 0.88 & 0.97 & 0.23 & 0.30 & 0.65 & 0.85 & 0.91 & 0.40 \\
12 & 0 & 0.22 & 0.42 & 0.94 & 0.18 & 0.13 & - & 0.45 & 0 & 0 & 0.13 & 0.35 & 0.46 & 0 \\
13 & 0 & 0.12 & 0.46 & 1 & 0.04 & 0.03 & 0.55 & - & 0 & 0 & 0 & 0.34 & 0.51 & 0 \\
14 & 0.68 & 1 & 1 & 1 & 1 & 0.77 & 1 & 1 & - & 0.59 & 1 & 1 & 1 & 0.69 \\
15 & 0.60 & 1 & 1 & 1 & 1 & 0.70 & 1 & 1 & 0.41 & - & 1 & 1 & 1 & 0.61 \\
16 & 0.14 & 0.68 & 0.97 & 1 & 0.60 & 0.35 & 0.87 & 1 & 0 & 0 & - & 0.82 & 0.91 & 0.16 \\
17 & 0 & 0.32 & 0.62 & 1 & 0.25 & 0.15 & 0.65 & 0.66 & 0 & 0 & 0.18 & - & 0.64 & 0 \\
18 & 0 & 0.20 & 0.46 & 1 & 0.14 & 0.09 & 0.54 & 0.49 & 0 & 0 & 0.09 & 0.36 & - & 0 \\
19 & 0.49 & 1 & 1 & 1 & 0.95 & 0.60 & 1 & 1 & 0.31 & 0.39 & 0.84 & 1 & 1 \\
\hline
\end{tabular}

TABle 6: Performance ranking of 20 banks with equal weights.

\begin{tabular}{lc}
\hline DMU & Rank \\
\hline DMU1 & 1 \\
DMU2 & 4 \\
DMU3 & 1 \\
DMU4 & 9 \\
DMU5 & 1 \\
DMU6 & 11 \\
DMU7 & 1 \\
DMU8 & 15 \\
DMU9 & 1 \\
DMU10 & 8 \\
DMU11 & 6 \\
DMU12 & 14 \\
DMU13 & 12 \\
DMU14 & 2 \\
DMU15 & 3 \\
DMU16 & 7 \\
DMU17 & 10 \\
DMU18 & 13 \\
DMU19 & 5 \\
DMU20 & 1 \\
\hline
\end{tabular}

TABLE 7: The unequal weights of inputs and outputs.

\begin{tabular}{lccccc}
\hline Indicators & $w_{1}$ ASST & $w_{2}$ EQTY & $w_{3}$ DEPO & $v_{1}$ LOAN & $v_{2}$ PROF \\
\hline Weights & 0.25 & 0.35 & 0.4 & 0.3 & 0.7
\end{tabular}

DMUs, but it fluctuates the inefficiency scores. In other words, both bounds of strictly efficient DMUs and the upper bound of weakly efficient DMUs maintain their effectiveness under any weight.

\section{Conclusion}

Most commonly used conventional DEA models assume that input-output data are precise and nonnegative, but in complex situations, it is not always possible that this assumption is satisfied. The literature suggests that several models are developed to handle the problem of imprecise and negative data. However, till yet, there are seldom models
TABLE 8: Interval efficiency, classification, and rank for 20 banks with unequal weights.

\begin{tabular}{lccc}
\hline DMU & Efficiency & Classification & Rank \\
\hline DMU1 & {$[1,1]$} & $E^{++}$ & 1 \\
DMU2 & {$[0.693,1]$} & $E^{+}$ & 4 \\
DMU3 & {$[1,1]$} & $E^{++}$ & 1 \\
DMU4 & {$[0.480,0.650]$} & $E^{-}$ & 9 \\
DMU5 & {$[1,1]$} & $E^{++}$ & 1 \\
DMU6 & {$[0.363,0.535]$} & $E^{-}$ & 11 \\
DMU7 & {$[1,1]$} & $E^{++}$ & 1 \\
DMU8 & {$[0.116,0.225]$} & $E^{-}$ & 15 \\
DMU9 & {$[1,1]$} & $E^{++}$ & 1 \\
DMU10 & {$[0.518,0.702]$} & $E^{-}$ & 8 \\
DMU11 & {$[0.483,1]$} & $E^{+}$ & 6 \\
DMU12 & {$[0.186,0.606]$} & $E^{-}$ & 14 \\
DMU13 & {$[0.352,0.520]$} & $E^{-}$ & 12 \\
DMU14 & {$[0.844,1]$} & $E^{+}$ & 2 \\
DMU15 & {$[0.779,1]$} & $E^{+}$ & 3 \\
DMU16 & {$[0.530,0.753]$} & $E^{-}$ & 7 \\
DMU17 & {$[0.387,0.600]$} & $E^{-}$ & 10 \\
DMU18 & {$[0.276,0.554]$} & $E^{-}$ & 13 \\
DMU19 & {$[0.660,1]$} & $E^{+}$ & 5 \\
DMU20 & {$[1,1]$} & $E^{++}$ & 1 \\
\hline
\end{tabular}

developed to handle imprecise data and negative data simultaneously. In this study, the IMSBM model is proposed to evaluate the relative efficiency of a set of DMUs with imprecise and negative data. The novelties of this model are that it could handle the data with these two mentioned characteristics simultaneously, and it puts aside the assumption of proportionate changes in inputs and outputs and deals with slacks directly, which ensures the efficiency obtained considering both radial and nonradial slacks. After restraining the limitation of conventional DEA models, the IMSBM model is more superior in practice.

This research proves that the IMSBM model is units invariant, monotone, and translation invariant. Moreover, the lower and upper bounds of the interval efficiency score are in the range of $[0,1]$, even with the existence of negative data. A numerical example illustrates the application of the IMSBM model, and the efficiency scores obtained are compared with those evaluated by the interval SORM model. 
Further classifying the DMUs into three subsets, the degree of preference approach is referenced as a simple and effective tool to rank the weakly efficient and inefficient DMUs. With the allowance to alter the input and output weights, we adjust them and find out that only the inefficient scores fluctuate with the weights.

Further work based on this paper is combining the IMSBM model with other theoretical studies that possess the abilities to weight slacks.

\section{Data Availability}

All the data used to support the models' application were collected by Hatami-Marbini et al. from different sources, including BANKSCOPE database. The data are included within the article (see Table 2).

\section{Conflicts of Interest}

The authors declare that there are no conflicts of interest regarding the publication of this paper.

\section{References}

[1] M. Baghery, S. Yousefi, and M. J. Rezaee, "Risk measurement and prioritization of auto parts manufacturing processes based on process failure analysis, interval data envelopment analysis and grey relational analysis," Journal of Intelligent Manufacturing, vol. 29, no. 8, pp. 1803-1825, 2018.

[2] A. Torres-Ruiz and A. R. Ravindran, "Use of interval data envelopment analysis, goal programming and dynamic ecoefficiency assessment for sustainable supplier management," Computers \& Industrial Engineering, vol. 131, pp. 211-226, 2019.

[3] W. W. Cooper, K. S. Park, and G. Yu, "IDEA and AR-IDEA: models for dealing with imprecise data in DEA," Management Science, vol. 45, no. 4, pp. 597-607, 1999.

[4] D. K. Despotis and Y. G. Smirlis, "Data envelopment analysis with imprecise data," European Journal of Operational Research, vol. 140, no. 1, pp. 24-36, 2002.

[5] A. Charnes, W. W. Cooper, and E. Rhodes, "Measuring the efficiency of decision making units," European Journal of Operational Research, vol. 2, no. 6, pp. 429-444, 1978.

[6] Y.-M. Wang, R. Greatbanks, and J.-B. Yang, "Interval efficiency assessment using data envelopment analysis," Fuzzy Sets and Systems, vol. 153, no. 3, pp. 347-370, 2005.

[7] G. R. Jahanshahloo, F. Hosseinzadeh Lotfi, M. Rostamy Malkhalifeh, and M. Ahadzadeh Namin, "A generalized model for data envelopment analysis with interval data," Applied Mathematical Modelling, vol. 33, no. 7, pp. 32373244, 2009.

[8] R. D. Banker, A. Charnes, and W. W. Cooper, "Some models for estimating technical and scale inefficiencies in data envelopment analysis," Management Science, vol. 30, no. 9, pp. 1078-1092, 1984.

[9] N. C. Petersen, "Data envelopment analysis on a relaxed set of assumptions," Management Science, vol. 36, no. 3, pp. 305314, 1990.

[10] N. Aghayi, M. Tavana, and M. A. Raayatpanah, "Robust efficiency measurement with common set of weights under varying degrees of conservatism and data uncertainty," $E u$ ropean Journal of Industrial Engineering, vol. 10, no. 3, pp. 385-405, 2016.
[11] H. Azizi and A. Amirteimoori, "Classifying inputs and outputs in interval data envelopment analysis," Journal of Industrial and Systems Engineering, vol. 10, no. 2, pp. 134-150, 2017.

[12] M. Toloo, E. Keshavarz, and A. Hatami-Marbini, "Dual-role factors for imprecise data envelopment analysis," Omega, vol. 77, pp. 15-31, 2018.

[13] A. Shabani, F. Visani, P. Barbieri, W. Dullaert, and D. Vigo, "Reliable estimation of suppliers' total cost of ownership: an imprecise data envelopment analysis model with common weights," Omega, vol. 87, pp. 57-70, 2019.

[14] K. Tone, "A slacks-based measure of efficiency in data envelopment analysis," European Journal of Operational Research, vol. 130, no. 1, pp. 498-509, 2001.

[15] F. H. Lotfi, G. R. Jahanshahloo, and M. Esmaeili, "Classification of decision making units with interval data using SBM model," Applied Mathematical Sciences, vol. 1, no. 14, pp. 681-689, 2007.

[16] H. Azizi, S. Kordrostami, and A. Amirteimoori, "Slacks-based measures of efficiency in imprecise data envelopment analysis: an approach based on data envelopment analysis with double frontiers," Computers \& Industrial Engineering, vol. 79, pp. 42-51, 2015.

[17] C. A. K. Lovell, "Measuring the macroeconomic performance of the Taiwanese economy," International Journal of Production Economics, vol. 39, no. 1-2, pp. 165-178, 1995.

[18] J. T. Pastor and J. L. Ruiz, "Variables with negative values in DEA," in Modeling Data Irregularities and Structural Complexities in Data Envelopment Analysis, J. Zhu and W. D. Cook, Eds., pp. 63-84, Springer, Boston, MA, USA, 2007.

[19] G. Cheng, P. Zervopoulos, and Z. Qian, “A variant of radial measure capable of dealing with negative inputs and outputs in data envelopment analysis," European Journal of Operational Research, vol. 225, no. 1, pp. 100-105, 2013.

[20] K. Kerstens and I. Van de Woestyne, "A note on a variant of radial measure capable of dealing with negative inputs and outputs in DEA," European Journal of Operational Research, vol. 234, no. 1, pp. 341-342, 2014.

[21] S. J. Tung, G. Y. Gan, W. L. Chyr, and H. S. Lee, "Efficiency measures for VRM models dealing with negative data in DEA," Journal of Marine Science and Technology, vol. 26, no. 2, pp. 180-184, 2018.

[22] J. A. Sharp, W. Meng, and W. Liu, "A modified slacks-based measure model for data envelopment analysis with 'natural' negative outputs and inputs," Journal of the Operational Research Society, vol. 58, no. 12, pp. 1672-1677, 2007.

[23] M. C. A. S. Portela, E. Thanassoulis, and G. Simpson, "Negative data in DEA: a directional distance approach applied to bank branches," Journal of the Operational Research Society, vol. 55, no. 10, pp. 1111-1121, 2004.

[24] A. Hatami-Marbini, A. Emrouznejad, and P. J. Agrell, "Interval data without sign restrictions in DEA," Applied Mathematical Modelling, vol. 38, no. 7-8, pp. 2028-2036, 2014.

[25] J. Zhu, "Imprecise data envelopment analysis (IDEA): a review and improvement with an application," European Journal of Operational Research, vol. 144, no. 3, pp. 513-529, 2003.

[26] C. Kao and S. T. Liu, "Fuzzy efficiency measures in data envelopment analysis," Fuzzy Sets and Systems, vol. 113, no. 3, pp. 427-437, 2000.

[27] R. Färe, S. Grosskopf, and C. A. K. Lovell, Production Frontiers, Cambridge University Press, Cambridge, UK, 1993. 
[28] A. Charnes and W. W. Cooper, "Programming with linear fractional functionals," Naval Research Logistics Quarterly, vol. 9, no. 3-4, pp. 181-186, 1962.

[29] A. I. Ali and L. M. Seiford, "Translation invariance in data envelopment analysis," Operations Research Letters, vol. 9, no. 6, pp. 403-405, 1990.

[30] Y.-M. Wang, J.-B. Yang, and D.-L. Xu, "Interval weight generation approaches based on consistency test and interval comparison matrices," Applied Mathematics and Computation, vol. 167, no. 1, pp. 252-273, 2005. 


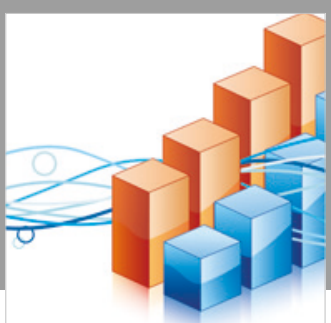

Advances in

Operations Research

\section{-n-m}
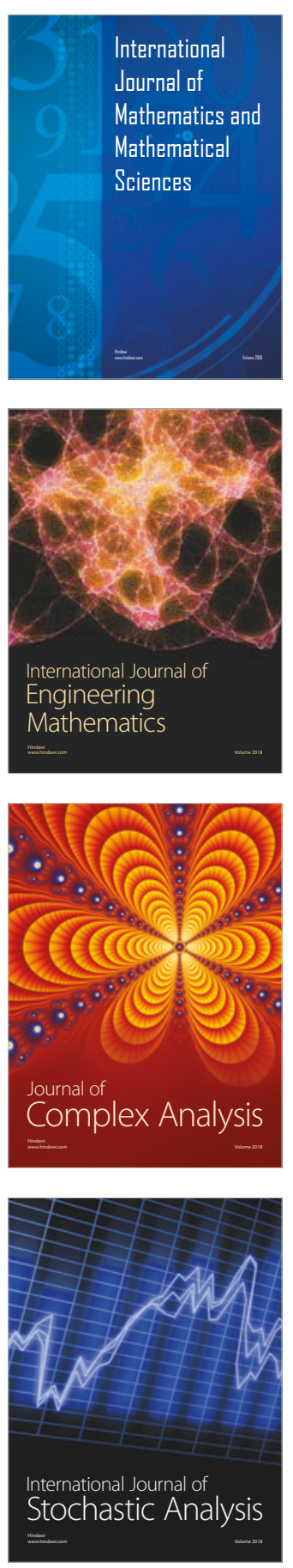
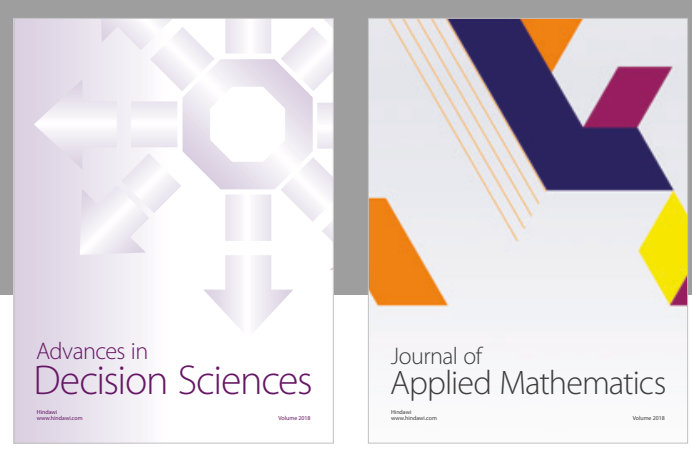

Journal of

Applied Mathematics
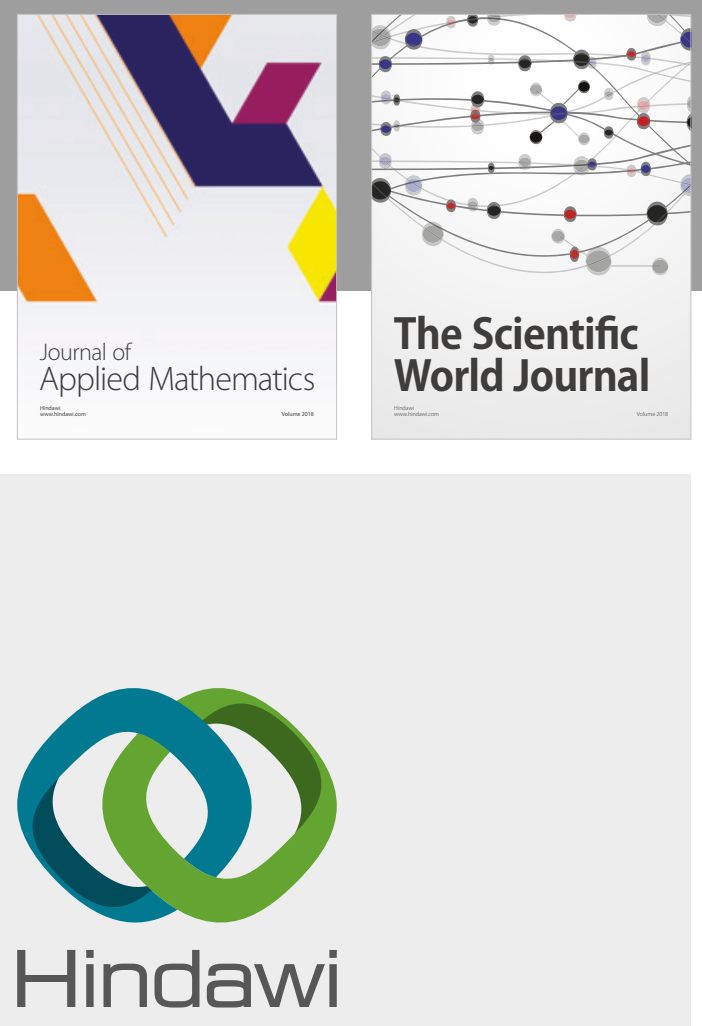

Submit your manuscripts at

www.hindawi.com

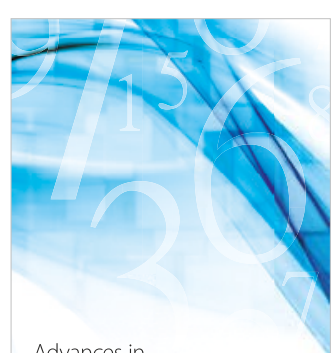

Advances in
Numerical Analysis
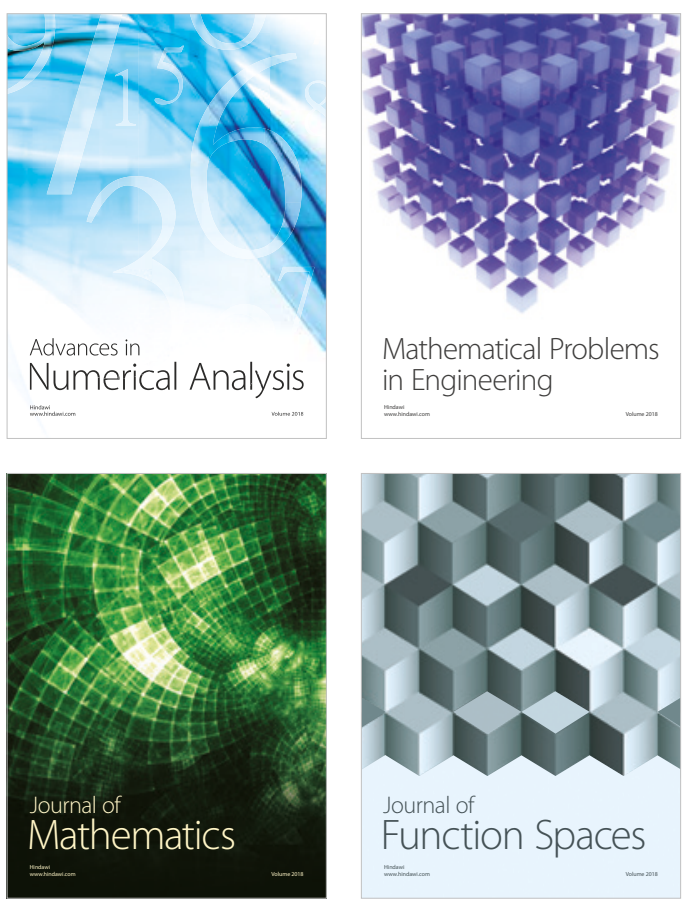

Mathematical Problems in Engineering

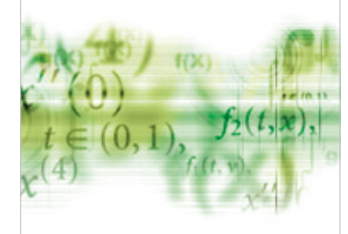

International Journal of

Differential Equations

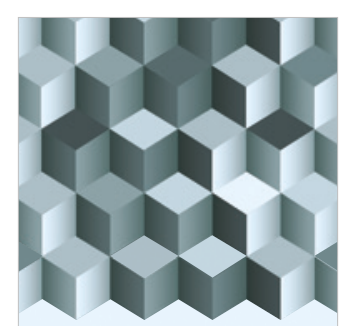

Journal of

Function Spaces

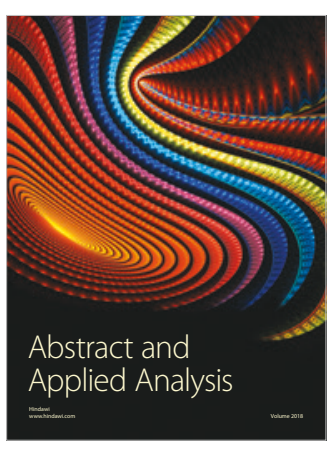

The Scientific

World Journal

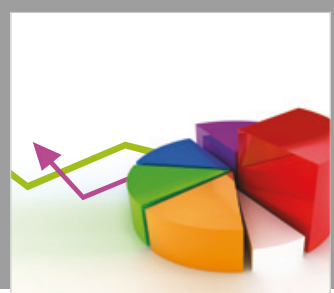

Journal of

Probability and Statistics
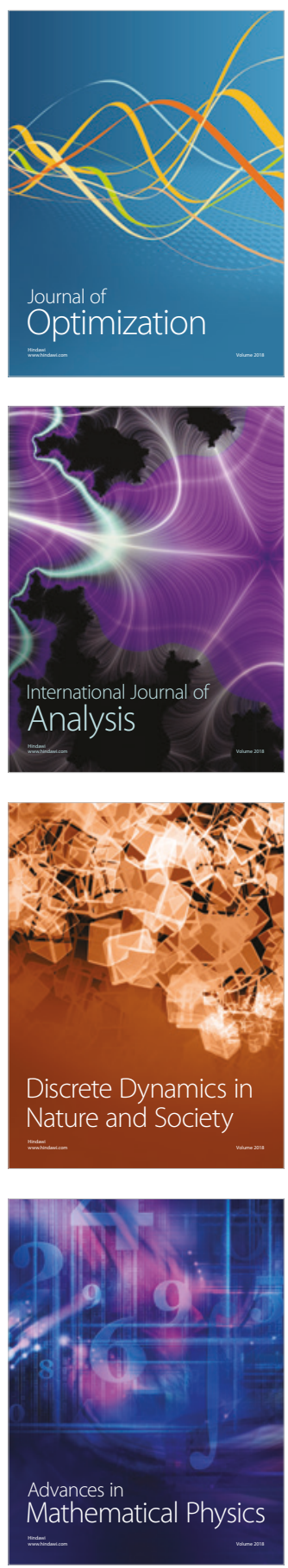